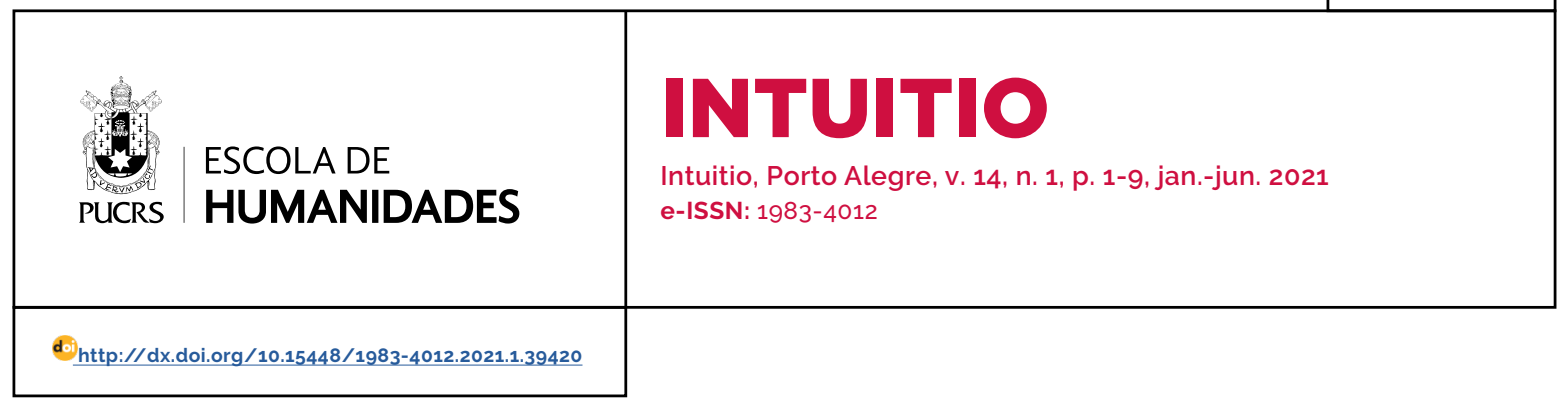

SEÇÃO: ARTIGO

\title{
Aceleração e constituição das subjetividades
}

\author{
Acceleration and constitution of subjectivities
}

\section{Giovan Longo ${ }^{1}$}

orcid.org/0000-0002-3306-9958

giovan.longo@edu.pucrs.br

Recebido em: 26 out. 2020. Aprovado em: 4 jul. 2021 Publicado em: 2 set. 2021.

\section{(c) (i)}

Artigo está licenciado sob forma de uma licença Creative Commons Atribuição 4.0 Internacional.
Resumo: O presente trabalho pretende discutir o fenômeno da aceleração no mundo contemporâneo a partir do pensamento de Hartmut Rosa, analisando os impactos da aceleração na constituição das subjetividades. Para tanto, partiremos de uma concepção de subjetividade estruturada a partir do pensamento de Emmanuel Levinas, refletindo como um mundo acelerado influencia na relação que estabelecemos com o outro e com o mundo e como isso impacta na própria constituição do eu. Ao longo do texto procuraremos, mesmo que de maneira mais geral, estabelecer uma relação entre conceito de ressonância proposto por Rosa e a ideia levinasiana de responsabilidade pelo outro.

Palavras-chave: Aceleração. Subjetividade. Ressonância. Responsabilidade.

Abstract: This paper intends to discuss the phenomenon of acceleration in the contemporary world from the perspective of Hartmut Rosa, analyzing the impacts of acceleration on the constitution of subjectivities. To do so, it will start from a conception of subjectivity structured from Levinas' thinking, reflecting how an accelerated world influences the relationship established with the other and with the world and how this impacts on the very constitution of the self. Throughout the text it is tried, even if more generally, to establish a relationship between the concept of resonance proposed by Rosa and the Levin asian idea of responsibility for the other.

Keywords: Acceleration. Subjectivity. Resonance. Responsibility.

\section{Introdução}

Parece que estamos cada vez com menos tempo. Ao acordar pela manhã, planejamos uma série de coisas e, ao final do dia, não conseguimos fazer tudo. Essa sensação de que nos faltou tempo aumenta se, ao invés de pensarmos naquilo que queriamos fazer em um dia, nos dedicarmos a pensar no que gostariamos de fazer em uma semana, um mês, um ano.

Cada vez mais surgem novas tecnologias que nos permitem realizar determinadas tarefas com maior rapidez. Mesmo assim, sentar-se na varanda para ler aquele livro que a tempos acumula pó na prateleira aparenta um sonho cada vez mais distante. Por que isso acontece? Por que, apesar de cronologicamente o tempo ainda ser o mesmo, esse mesmo tempo como o percebemos, parece estar cada vez mais acelerado?

E não é só isso! As novas tecnologias não mudam só a forma como percebemos o tempo. Mudam a forma como percebemos a nós mesmos. Quem somos, como somos, como deveremos ser também mudou. As novas tecnologias parecem impactar diretamente na forma como nos constituí- 
mos enquanto sujeitos e nos relacionamos com o mundo. Ao longo da vida mudamos. Modificamos quem somos. Nos ressignificamos. Isso é natural. Entretanto, parece que o mundo acelerado atual não nos dá o tempo necessário para essa transformação/ressignificação. Não há tempo para definir quem sou. As identidades se tornam liquidas. ${ }^{2}$

O presente trabalho é uma tentativa de refletir a respeito dessas questões, nos focando no tema da construção das identidades em um mundo acelerado. Nossas reflexões terão como base a obra Aceleração - a transformação das estruturas temporais na Modernidade do pensador Hartmut Rosa. ${ }^{3}$ Como a presente obra nos servirá de fundamentação teórica principal, seguiremos a estrutura da mesma, apresentando os conceitos conforme eles são desenvolvidos por Rosa ao longo dela. Conforme vamos desenvolvendo o texto, outros pensadores serão inseridos, a fim de aprofundar a reflexão.

\section{Um mundo acelerado}

Muitos são os autores que se dedicam a pensar o fenômeno da aceleração. Alguns defendendo as transformações que estão ocorrendo na medida em que o desenvolvimento tecnológico avança, como por exemplo aqueles que se autodenominam ou são denominados de aceleracionistas. ${ }^{4}$ Há uma diversidade de concepções e visões de mundo entre eles, mas pelo menos um ponto geral é comum: a confiança na tecnologia como positivamente transformadora da realidade e salvadora do mundo. Entretanto, para eles, ainda estamos longe do ideal. É preciso acelerar mais.

Para os aceleracionistas, senão para todos, para a maioria, a meta é a superação da própria humanidade em si. Precisamos transcender o humano e a tecnologia pode nos ajudar com isso. Conforme nos destacam Danowski e Castro,
Os aceleracionistas entendem que "nós" devemos escolher entre o animal que fomos e a máquina que seremos. Em sua angelologia materialista, eles propõem, em suma, um mundo sem nós, mas feito por nós. Reciprocamente, imaginam uma espécie pós-humana recriada por uma "plataforma material" hiper capitalista mas sem capitalistas. Sonham com uma humanidade extracorpórea, um mundo extraterrestre. Uma natureza desnaturalizada pelo ex-homem. Um materialismo, enfim, espiritualizado. ${ }^{5}$

Nem todos são tão otimistas quanto os aceleracionistas em relação ao avanço tecnológico, e aqui não se trata de ser catastrofista. É claro que muitas vozes se levantam contra qualquer desenvolvimento tecnológico maior, sobretudo quando tal desenvolvimento não é acompanhado por um desenvolvimento moral, questionando inclusive se as novas tecnologias que vão surgindo realmente melhoram nossa vida. ${ }^{6}$ Mas não são esses que nos interessam diretamente aqui. Quem nos interessa aqui são aqueles pensadores que reconhecem no desenvolvimento tecnológico inúmeros benefícios, mas que, ao mesmo tempo, nos pedem para termos cuidado, refletirmos bastante a respeito do que estamos fazendo e não nos deixarmos "enfeitiçar" pelo "canto da sereia" que pode ser a tecnologia, ou seja, não esquecermos de analisar também os possiveis impactos negativos advindos de determinados avanços.

Hartmut Rosa é um desses pensadores. Mais especificamente o que nos interessa aqui nele são dois aspectos de sua análise. Em primeiro lugar, seu objetivo primeiro é compreender fenomenologicamente todas as mudanças ocasionadas pelos processos de aceleração ao longo do tempo. Isso significa que, antes de qualquer juizo de valor, é preciso identificar e analisar as estruturas que constituem esses processos. O que nos leva ao segundo aspecto, que nos faz recorrer a ele como fio condutor de nossa reflexão: a compreensão do fenômeno da aceleração não pode ser obtida analisando apenas

\footnotetext{
Q Queremos fazer menção aqui às reflexões de Zygmunt Bauman a respeito do "mundo líquido", algo presente em praticamente toda a sua obra. Para informações mais especificas ver BAUMAN, 2001

3 ROSA, 2019

Conhecidos por outras denominações, como por exemplo Singularitanos, têm como alguns de seus representantes T. Nordhaus, M. Shellenberger e Ray Kurzweil.

- De maneira mais ou menos radical encontramos nomes como Francis Fukuyama e Michael Sandel, denominamos muitas vezes como bioconservadores. Eles não são contra a tecnologia (tecnofóbicos). Mas demonstram certo pessimismo quanto ao que se desenha enquanto futuro do desenvolvimento tecnológico.
} 
um aspecto ou dimensão, por exemplo, nos atendo apenas à aceleração tecnológica. A questão é mais complexa e demanda uma análise maior. A aceleração se dá em várias dimensões, é de vários tipos. Voltaremos a essa questão mais tarde.

Para Rosa, vivemos em um mundo marcado cada vez mais pela busca constante de crescimento e inovação. Aparentemente, isso parece ser "natural" na medida em que o sistema econômico sob o qual vivemos exige isso. O capitalismo tem no lucro e no crescimento constante alguns de seus fundamentos. O problema, ou melhor, um dos problemas disso, é que estamos em um estágio do capitalismo em que esse crescimento e essa inovação não nos proporcionam um "mundo melhor", com melhores condições a todos. ${ }^{7}$

Na verdade, para o pensador, o mundo em que vivemos exige que aceleremos cada vez mais para permanecer onde estamos. Aceleramos para buscar uma estabilização, para não decrescermos social e economicamente. A lógica da concorrência marca o mundo atual e tal concorrência ocorre a um nivel individual, subjetivo. Diferente de outros periodos da história, onde status e posição social eram definidos no nascimento, agora eles são constantemente, segundo o próprio Rosa,

[...] reatribuidos segundo a lógica da concorrência. Crescimento, aceleração e adensamento de inovações, enquanto traços constitutivos do "imperativo dinâmico" estrutural da sociedade moderna, se traduzem para o âmbito da condução da sociedade moderna, se traduzem para o âmbito da condução subjetiva da vida por via da competição por atribuições: não apenas de bens e recursos, mas também de privilégios e posições, de status e reconhecimento, de amizades e parceiros amorosos. ${ }^{8}$

\section{É claro que em um primeiro momento, o fato de} não mais vivermos em uma sociedade que determina nosso status a partir do nascimento parece ser bastante positivo. Afinal, agora somos "livres" para decidirmos sobre o que queremos ser, que profissão queremos seguir e mesmo para buscar melhores posições sociais independentemente de nossa origem. Ao menos essa é a promessa, o que nos faz - ou deveria fazer - questionar: o quão realmente somos mais livres? O quão real é a possibilidade de mobilidade social?

Podemos escolher nossa profissão, por exemplo, mas conseguir exercê-la depende de uma série de variáveis e contextos que estão muito além da simples vontade. Além disso, e Rosa é assertivo em suas reflexões, ainda permanece a importância dada ao status. Ainda permanece a necessidade de buscar determinados status sociais para ser reconhecido enquanto sujeito, enquanto pessoa. Ou seja, a sociedade continua estratificada, com a diferença de que agora há a promessa sedutora de que podemos mudar as condições nas quais nascemos. Uma promessa cruel na medida em que ignora tudo aquilo que envolve a (in)possibilidade de mobilidade social, responsabilizando os sujeitos pelo sucesso ou fracasso nessa empreitada.

Entretanto, a busca por um status melhor na sociedade está se tornando uma busca quase que secundária. Como já dissemos, o sujeito no mundo atual precisa, em um primeiro momento, lutar para permanecer onde está, para não descender. Isso ocorre em nivel de Estado-nação um país brigando pela soberania econômica com outro -ou mesmo a um nivel individual.

É necessário desempenhar sempre um pouco
mais e, para tal, investir mais energia que o
concorrente - que, por sua vez, deverá forçar
a competição ainda mais. Essa lógica se deixa
observar em todos os lugares: de forma espe-
cial nas práticas educacionais, mas também no
trato com o próprio corpo. O que no esporte se
chama doping, em outras esferas sociais se cha-
ma human enhancement. A espiral de aumento
concorrencial induzida é infindável. Se não su-
perarmos o modo dominante de estabilização
dinâmica através de uma revolução econômica,
política e cultural, com grande certeza, já em

\footnotetext{
7 É claro que, neste ponto, precisamos nos questionar se isso, em algum momento da história do capitalismo sob a Terra, aconteceu de forma homogênea. O sistema é explorador desde o seu início e busca beneficiar alguns a partir da exploração da maioria. Faz parte da identidade do sistema. Podemos, é claro, também nos perguntar a respeito de qual sistema, no contexto atual, poderia substituir o capitalista. Alguns, como por exemplo Gilles Lipovetsky, dirão que não há qualquer perspectiva de novo sistema capaz de substituir o capitalista e, portanto, toda transformação deve ocorrer no interior dele. Outros vão afirmar que uma nova organização não só é possivel, como necessária. Apesar de considerarmos de suma importância tal debate, aqui não vem ao caso. Nosso objetivo é refletir a respeito do fenômeno da aceleração na sociedade atual, o que implica não em discutir qual é o melhor sistema econômico, mas em analisar a atual forma de organização da sociedade, buscando compreender o fenômeno da aceleração e como ele impacta na constituição das subjetividades. 8 ROSA, 2019, p. XXI, grifo do autor.
} 
poucos anos, equiparemos nossas crianças biotecnologicamente, bem como com o auxilio de tecnologias educacionais. ${ }^{9}$

Uma sociedade que funciona dessa forma exige cada vez mais um mundo acelerado. As próprias estruturas temporais são afetadas. A aceleração, para Rosa, tem como princípio a emancipação do tempo em relação ao espaço. ${ }^{10} \mathrm{~A}$ forma como percebemos o tempo e lidamos com ele se modifica na medida em que necessitamos cada vez de mais tempo, percebendo-o cada vez mais rápido enquanto, cronologicamente, ele permanece constante. Em outras palavras, necessitamos de uma quantidade de tempo cada vez maior, mas o tempo enquanto recurso é limitado. Essa mudança na percepção temporal cria algo de paradoxal:

Pode-se ilustrar o problema da transposição e de sincronização induzido pela aceleração através de exemplos simples. Geralmente, quase todo cidadão deseja, como cliente (na estação, num café, no médico, no auxilio telefônico etc.), ser atendido o mais rápido possivel - e, por outro lado, ter o máximo de tempo e o mínimo de estresse no trabalho (ou seja, como prestador de serviços). Essa ideia - de que tudo deve andar o mais rápido possivel para que eu tenha mais tempo - é, num nivel coletivo, claramente contraditória. ${ }^{11}$

Tal aceleração aparece nas sociedades de três formas. Uma primeira forma é a da aceleração técnica, marcada entre outras coisas pela aceleração dos processos de transporte, comunicação e produção. ${ }^{12} \mathrm{O}$ próprio estar no mundo é modificado a partir da aceleração técnica na medida em que as distâncias parecem diminuir. Tempo e espaço são cada vez mais desvinculados. Uma segunda forma é a da aceleração do ritmo da vida, definida como "[...] aumento dos episódios de ação e/ou de experiência por unidade de tempo [...]".13 Por fim, a terceira forma de aceleração diz respeito à aceleração social e cultural, que
[...] se tornou um processo autopropulsor, que dispõe as três áreas da aceleração numa interação circular, na qual se relacionam no sentido de aumento. A aceleração dentro desse circulo gera, assim, sempre e inevitavelmente, mais aceleração, tornando-se um "sistema de feedback" que se fortalece a si mesmo. ${ }^{14}$

Isso significa que a compreensão do processo de aceleração não se dá analisando apenas um dos tipos isolados. Há uma relação entre eles que precisa ser levada em consideração. A aceleração técnica, por exemplo, provoca o surgimento de novas tecnologias que nos permitem realizar determinadas tarefas em menos tempo, o que faz com que consigamos realizar cada vez mais tarefas em um determinado periodo, provocando assim também uma aceleração do ritmo da vida.

Tudo o que foi dito até agora nos serve de contextualização do atual período em que vivemos. É em meio a tal contexto que construímos nossa identidade, que definimos ou construímos quem somos. Nosso próximo passo, é refletir a respeito das implicações resultantes do processo de aceleração na constituição de nosso eu. Seguiremos tendo como base teórica principal as reflexões desenvolvidas por Rosa. Entretanto, dialogaremos com outros pensadores, sobretudo durante a definição de alguns termos que serão utilizados durante a reflexão

\section{A constituição das subjetividades em um mundo acelerado}

O que significa ser eu, ser um sujeito, ter uma subjetividade, varia ao longo da história da filosofia. Tendo presente isso, antes de mais nada, é preciso deixar claro o que entendemos aqui por subjetividade. Nossa definição de subjetividade é influenciada diretamente pelo pensamento levinasiano. A escolha por Emmanuel Levinas se dá pela concordância que temos para com seu pensamento. Ter uma

\footnotetext{
9 ROSA, 2019, XXII. Os problemas aqui são muitos. A aceleração em si já traz graves problemas àqueles que aparentemente conseguem acompanhar o ritmo. Mas, e o próprio Rosa questiona em muitos momentos, e aqueles grupos sociais que não querem ou não podem acelerar? Em um nível político também surgem alguns problemas. Um mundo acelerado é um mundo em que a democracia está em risco. O processo democrático leva tempo, mais tempo do que estão dispostos aqueles que "precisam" acelerar cada vez mais.

10 ROSA, 2019, p. 58

11 ROSA, 2019, p. 35, grifo do autor. A citação se refere a uma nota de rodapé - nota 62

12 ROSA, 2019, p. 189.

13 ROSA, 2019, p. 239.

14 ROSA, 2019, p. 302
} 
subjetividade, aqui neste trabalho, significará ter uma identidade própria, ter um eu único, marcado pela diferença em relação aos outros.

Entretanto, tal subjetividade não é construida de maneira isolada. Ela surge e se reconstrói na relação com os outros. O outro, aquele também de subjetividade própria e única que vem ao meu encontro, é fundamental para que minha subjetividade "se desenvolva", "nasça". Sou o que sou no contato com outro diferente de mim. Aqui, a diferença não é um problema. O problema é pensar que a diferença é um problema. Além disso, a relação que estabelecemos com os outros é indispensável, na medida em que sem o outro, não sou eu.

Guardadas as proporções e tendo em mente que qualquer relação mais definitiva demandaria um trabalho à parte, parece-nos, em um primeiro momento de contato com os conceitos de Rosa, que o conceito de alteridade levinasiano é próximo em alguns aspectos ao conceito de ressonância. Essa proximidade em alguns aspectos não exclui, é claro, as diferenças existentes, que vão desde a justificação de tais conceitos até onde cada um dos autores busca os fundamentos de seu pensamento. ${ }^{15}$

Rosa entende a ressonância como "[...] um modo relacional no qual sujeito e mundo colocam-se numa relação responsiva [...]".16 Os seres humanos, para ele, "[...] buscam e realizam experiências que possuem significado central para eles [...]".17 $\mathrm{O}$ encontro com o outro, que se dá nessa relação de ressonância e é marcado pela responsabilidade, tem como objetivo ou resultado uma relação mútua. ${ }^{18}$

O que nos interessa aqui em termos de aproximação com o pensamento levinasiano é esse lugar da responsabilidade que nos parece central também no que Rosa define como ressonância. Além disso, mesmo tomando caminhos distintos, ambos os pensadores veem na relação com o outro algo de essencial para a constituição da própria identidade. Isso nos permite, entre outras coisas, manter como significado de subjetividade aqui neste texto, aquele dado por Levinas. ${ }^{19}$

Ainda sobre a ressonância, para Rosa

[...]. Não se pode confundir ressonância com consonância ou harmonia: ela não significa concordância ou fusão, antes significa resposta, e, enquanto tal, engloba constitutivamente contradição e dissonância.

Com isso, podemos resumir: ressonância diz respeito a um modo de relação com o mundo no qual sujeito e mundo "alcançam-se" mutuamente, de tal modo que uma relação responsiva, que produza efeitos transformativos, pois que liquefaz as já dadas relações do mundo, emerja. Em relações de ressonância, os sujeitos são tocados (afetados) por um outro, o qual os refere e the diz algo, ao mesmo tempo que respondem (emocional e fisicamente) e, com isso, experienciam-se como autoeficazes. Indisponibilidade revela-se uma característica constitutiva de uma tal relação: esta não se deixa ordenar politicamente, nem se criar instrumentalmente. Ressonância pode ocorrer sob condições desfavoráveis, bem como ausentar-se sob condições favoráveis. No entanto, todas as culturas dispõem de contextos institucionais especificos de práticas sociais nas quais experiências de ressonância tornam-se prováveis. [...].20

Quatro são os elementos centrais de uma relação de ressonância: a afetação, que diz respeito a um chamado que vem de fora onde o sujeito sente-se internamente tocado, movido ou tomado; a autoeficácia, que diz respeito à resposta que o sujeito dá à afetação; a transformação, que se refere à transformação ocorrida a partir da relação responsiva em que o eu e o mundo se

\footnotetext{
A aproximação que será feita daqui em diante entre a noção levinasiana de alteridade e a noção de ressonância de Rosa deve ser analisado com muito cuidado. É uma primeira tentativa de aproximação feita a partir de um contato bastante inicial com o pensamento de Hartmut Rosa e sem a análise de seu livro principal a respeito do tema por, infelizmente até o momento, não termos conseguido acesso à obra. Nos limitaremos, portanto, ao que Rosa nos adianta no livro Aceleração. Sabemos que com isso qualquer tentativa de aproximação ficará bastante superficial. Entretanto, também entendemos que será importante para nosso percurso investigativo pessoal, mesmo que depois, em algum momento, tenhamos que rever alguns pontos do presente trabalho. Já temos consciência, entretanto, que as diferenças são grandes, até mesmo porque os fundamentos de cada uma das noções são totalmente distintos. Entretanto, e é por isso que nos arriscamos a tal aproximação, nos parece, até agora, que tais noções não são excludentes. Se não podem ser totalmente relacionadas, é possivel trabalhá-las para que estejam em diálogo.

16 ROSA, 2019, p. XXXI.

17 ROSA, 2019, p. XXXII.

18 ROSA, 2019, p. XXXV. Fizemos aqui vários recortes do texto deixando de lado os momentos em que Rosa compara ou discute o conceito de ressonância lado a lado com o conceito de reconhecimento de Honneth. Optamos por esses recortes tendo em vista o objetivo do presente texto. Entretanto, é necessário fazer menção a isso, destacando que, para Rosa, antes do reconhecimento, o que se busca em uma relação é a ressonância.

19 Sobre os temas da alteridade e da responsabilidade em Levinas, ver LONGO, 2019 (ver referências).

20 ROSA, 2019, p. XL, grifo do autor. Essa espécie de "condicionalidade" da ressonância, quando mais bem compreendida, pode ser um ponto significativo de distanciamento entre Rosa e Levinas.
} 
transformam; e, por fim, a indisponibilidade que tem dois sentidos principais: a ressonância não pode ser imposta e as relações de ressonância são imprevisiveis em relação ao resultado. ${ }^{21}$

Relações de ressonância, que são fundamentais na constituição das subjetividades, demandam tempo. Em um mundo acelerado, essas relações e, como consequência, a própria constituição de quem eu sou, são diretamente afetadas. "[...] não se pode, ao mesmo tempo, concorrer e ressoar com alguém. [...] medo, estresse e pressão temporal são, por excelência, 'algozes da ressonância': eles impõe um fechamento disposicional contra qualquer coisa que não seja voltada a um fim predefinido [...]".22

Os sujeitos se veem, assim, em um mundo que não lhes dá tempo para construir uma identidade. Muitos se veem obrigados a adotar uma identidade muitas vezes fabricada, que não retrata quem eles realmente são, mas que serve de passe para a entrada na dinâmica social que tem como promessa o sucesso e o crescimento baseados na ideia de que só o esforço basta. Como consequência, há a massificação dos sujeitos, se quisermos recorrer aqui aos teóricos da Escola de Frankfurt, ${ }^{23}$ ou mesmo há uma totalização das identidades, pensando mais uma vez aqui em Levinas; com a diferença, é claro, que não se trata de um sujeito impondo seu eu ao outro, mas de uma imposição da sociedade sobre o indivíduo. ${ }^{24}$

A aceleração, além de transformar nossas relações com o espaço, transforma também nossa relação com os outros e com o mundo que, como vimos, é essencial para a construção e permanente ressignificação de nossa identidade. Tudo se torna transitório, mutável, contingente. Mudar quem somos, ou seja, possuir uma subjetividade que não é estática e definitiva, que está em permanente transformação é, mesmo que nos mínimos aspectos, natural. Faz parte daquilo que chamamos de "amadurecimento" ou "crescimento" pessoal. Entretanto, é preciso tempo para estabelecer uma identidade a ser mudada. Ou seja, não podemos mudar quem somos se antes não constituímos um eu a ser mudado. Ao que parece, no atual nivel de aceleração que nos encontramos, não há esse tempo para a constituição do eu.

Estabelecer uma relação autêntica com alguém, que seja verdadeiramente de alteridade, que ressoe, exige dos sujeitos um contato desinteressado, sem a preocupação com a apresentação de uma "imagem" fabricada a partir de um desejo de exposição personalizada que visa apenas uma determinada quantidade de likes, por exemplo. Mas como fazer isso se, na busca por um reconhecimento artificial as pessoas perdem a noção de quem realmente são, deixando de lado sua própria identidade ao buscar identificar-se com personas criadas também artificialmente a fim de servirem de combustivel para a aceleração em seus variados niveis e tipos?

As redes sociais são um bom indicativo desse contexto que estamos tentando descrever. Há sujeitos que se tornam irreconheciveis no "mundo digital". Suas postagens, suas ideias e seu comportamento às vezes parecem "vir de outra pessoa", duplicar sua personalidade a ponto de não sabermos mais quem elas realmente são. Será que são aquelas que se apresentam no face a face? Ou elas são aquilo que se mostram nas redes sociais? Desconfiamos que, em um dado momento, nem mesmo elas conseguiriam responder.

É claro que aqui estamos destacando apenas os aspectos negativos dos exemplos utilizados. É inegável que os avanços tecnológicos também possuem dimensões positivas. As redes sociais, por exemplo, nos permitem entrar em contato com pessoas de todos os lugares do mundo. Podemos viajar e conhecer culturas de uma forma que poucos imaginavam ser possivel alguns séculos atrás. O próprio Rosa destaca que considerar a aceleração em si como benigna ou maligna depende de alguns fatores:

Se a aceleração em si é julgada como uma transformação temporal maligna ou benigna

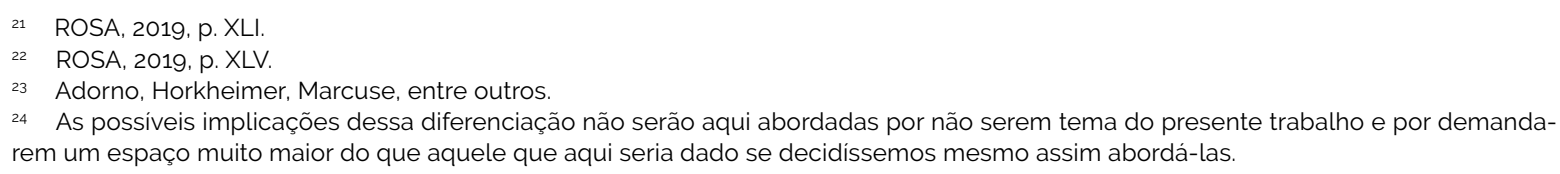


depende, obviamente, das consequências que se leva em consideração. Da perspectiva da finitude de vida humana, pressupõe-se que a aceleração de processos orientados a um propósito (como a produção de bens ou condições, a suplantação de distâncias para o transporte ou a transmissão de informações) será percebida fundamentalmente como desejável. No entanto, um perigo evidente nesse caso consiste na possivel dessincronização de processos, sistemas e perspectivas em razão de aceleração unilateral. A aceleração de um único setor da sociedade é socialmente aceitável apenas quando aumentos de velocidade correspondentes são "traduzidos", sem atrito, entre os limiares estruturais e culturais. ${ }^{25}$

Rosa vai falar da busca por uma forma diferente daquela atual desestabilização no processo de aceleração. Para ele, sociedades mudam. Elas não podem permanecer estáticas sob o risco de desaparecem diante das transformações que ocorrem no mundo. Entretanto, as mudanças deveriam ser buscadas apenas quando for necessário, não como um modo de existência. É o que ele vai chamar, ao longo da obra utilizada aqui como referência central, ${ }^{26}$ de uma mudança de uma estabilização dinâmica para uma estabilização adaptativa.

No que se refere especificamente à constituição da subjetividade, tal estabilização poderia proporcionar mais tempo para isso, eliminando assim a necessidade de se adotar uma identidade artificial que seja "mais competitiva". Dito de outra forma e recorrendo ao exemplo das redes sociais, de nada adianta conhecermos mais pessoas, se a relação com elas não for de ressonância, mas de competição para ver qual é o melhor perfil, quem recebe mais curtidas ou quem tem o maior número de seguidores. Assim também é em relação ao contado com diferentes culturas. Não há qualquer efeito positivo para a constituição das subjetividades nesse contato se eu não estiver disposto a reconhecer no modo como o outro vive e compreende o mundo, um modo autêntico e digno de respeito. As relações, nesse sentido, precisam ser de alteridade; não comerciais ou objetificadas.

É claro que, independentemente do juizo de valor que se faça à aceleração, as constantes transformações em um mundo acelerado são de qualquer forma um desafio à constituição das subjetividades. As mudanças que ocorrem nas sociedades hoje são intrageracionais. Isso significa que, dentro de uma mesma geração ocorrem mudanças profundas nas concepções de mundo, exigindo cada vez mais dos sujeitos uma capacidade adaptativa em relação a esse sempre "novo mundo" e às pessoas ao seu redor. Nada impede que subjetividades sejam formadas em um contexto assim, mas é novamente preciso tempo e estabelecimento de relações de ressonância.

Além disso, como o próprio Rosa afirma, um desafio maior se dá nas relações entre gerações, uma vez que, cada vez mais, a diferença entre uma e outra aumenta.

[...] jovens e idosos vivem cada vez mais em
submundos isolados entre si, não apenas por
utilizarem diferentes meios de comunicação,
mas ainda por jogarem diferentes jogos e fre-
quentarem diferentes lugares, assistirem a dife-
rentes programas de televisão, lerem diferentes
periódicos, preferirem distintos estilos musicais
em ambientes divergentes, usarem outras rou-
pas, compradas em lojas especializadas para
sua faixa etária, eaté mesmo comerem comidas
diferentes, além de falarem uma outra lingua. ${ }^{27}$

Se levarmos em consideração que o contato com o outro diferente do eu é também o contato com o outro de uma idade, perspectiva de vida etc. diferente, poderemos ter uma noção do que significa esse diagnóstico em termos de constituição do eu.

A forma como os sujeitos concebem quem são, nesse sentido muda drasticamente. As mudanças intrageracionais fazem com que os individuos se mantenham "[...] abertos, flexiveis e simpáticos a mudanças, caso contrário correm o risco de sofrer permanentes frustrações sempre que suas concepções identitárias ameaçarem fracassar em um ambiente em rápida transformação [...]".28

A exigência de mudança em si não parece ser o problema. O problema é o motivo dessa exigência, o porquê adaptar ou mudar aquilo que

\footnotetext{
ROSA, 2019, p. 35, grifo do autor.

ROSA, 2019

ROSA, 2019, p. 224

ROSA, 2019, p. 298
} 
os sujeitos são. Se a mudança for devido à necessidade de competição e de manutenção de um status em meio a um mundo acelerado, ai sim há problemas. Isso porque o sujeito se vê obrigado a transformar sua identidade. Tal transformação não ocorre a partir de uma relação de alteridade marcada pela ressonância. Não há afetação, pois

Nesse ponto parecem se agrupar todos aqueles elementos que caracterizam, no diagnóstico das identidades pós-modernas, a liquefação das estruturas da identidade, antes estáveis, em favor de relações identitárias mais abertas, mais experimentais, mais fragmentárias e sobretudo cada vez mais transitórias, que refletem a dinâmica dos frenéticos "fluxos globais". Douglas Kellner formula nesse sentido: "A identidade hoje [...] se torna um jogo escolhido deliberadamente, uma apresentação teatral de si mesmo, na qual o individuo pode se apresentar em uma variedade de papéis, imagens e atividades de forma relativamente despreocupada com substituições, transformações e mudanças dramáticas" [...].29

Para Rosa, os sujeitos, no contexto acelerado atual, desenvolvem assim uma identidade situacional que é flexivel e se adapta de acordo com as necessidades do momento. Até mesmo as posições políticas ou filosóficas perdem sua estabilidade. A subjetividade é, portanto, estruturada a partir de necessidades artificiais e impostas, em meio a uma sociedade cada vez mais acelerada, dentro de um mundo líquido de identidades também líquidas. Isso representa, entre outras coisas, uma perda da própria autonomia. ${ }^{30}$

Assim como no que se referiu a algumas ideias anteriores, a identidade situacional em si não é necessariamente um problema. O que podemos e devemos questionar são as exigências advindas das necessidades da sociedade acelerada muito mais preocupada como seu desenvolvimento do que com o desenvolvimento pessoal dos sujeitos. Uma identidade reconstruida constantemente, se adaptando às situações conforme elas vão acontecendo, sem reflexão e autonomia, pode fazer com que o sujeito perca a noção de quem é. "Ser..." como "sendo no momento..." nos leva à alienação do que somos, à perda de nossa indivi- dualidade e unicidade e à adoção de identidades fabricadas, oferecidas ou vendidas de acordo com as necessidades do sistema.

\section{Considerações finais}

Ao longo do texto, procuramos mostrar como as subjetividades se constituem em uma sociedade marcada pela aceleração constante. Utilizamos como fio condutor as reflexões desenvolvidas por Hartmut Rosa, no livro Aceleração. Entretanto, é preciso destacar, nem sempre nos mantivemos fiéis a ele. Procuramos dialogar com outros autores e pensadores, fazendo, em alguns momentos, alguns juízos de valor que o próprio autor se abstém de fazer dada a natureza e os objetivos de sua obra.

Rosa nos dá muito o que pensar. Aqui destacamos o tema da constituição da subjetividade. Mas outros temas emergem na medida em que acompanhamos o desenvolvimento de suas reflexões através de um método verdadeiramente fenomenológico de compreensão da forma como percebemos o mundo e a nós mesmos.

Por fim, é preciso destacar que as reflexões presentes neste texto não são definitivas. Nasceram de um primeiro contato com o autor, portanto, ainda podem conter elementos e relações que precisam ser revistos ou mais bem desenvolvidos. Pedimos desculpas por isso. Entretanto, um primeiro esboço do que compreendemos até aqui se fazia necessário ao menos para fins individuais, segundo os interesses daquele que escreve. Se servir ao leitor como base para outras reflexões, excelente. Senão, que seja ao menos um texto a ser questionado, levando o leitor a entrar em contato com a obra de Rosa.

\section{Referências}

ADORNO, Theodor; HORKHEIMER, Max. Dialética do Esclarecimento. Rio de Janeiro: Zahar, 2006.

BAUMAN, Zygmunt. Modernidade Liquida. Rio de janeiro: Jorge Zahar, 2001 
BAUMAN, Zygmunt. Identidade: Entrevista a Benedetto Vecchi. Tradução de Carlos. Alberto Medeiros. Rio de Janeiro: Zahar, 2005

DANOWSKI, Déborah; CASTRO, Eduardo Viveiros de. Há um mundo por vir?: ensaios sobre os medos e os fins. Florianópolis: Cultura e Barbárie: Instituto Socioambiental, 2014

LEVINAS, Emmanuel. De otro modo que ser o más allá de la esencia. Tradução de Antonio Pintor Ramos. Salamanca: Sígueme, 2011.

LONGO, Giovan. A anterioridade da responsabilidade em Emmanuel Levinas. Porto Alegre: Editora Fi, 2019.

ROSA, Hartmut. Aceleração: A transformação das estruturas temporais da Modernidade. Tradução de Rafael H. Silveira. São Paulo: Editora Unesp, 2019.

TÜRCKE, Christoph. Sociedade Excitada: filosofia da sensação. Campinas: Ed. Unicamp, 2010.

\section{Giovan Longo}

Mestre em filosofia pela Pontifícia Universidade Católica do Rio Grande do Sul (PUCRS), em Porto Alegre, RS, Brasil; doutorando em filosofia na PUCRS; professor de filosofia nos colégios Marista Assunção e Marista Rosário, em Porto Alegre.

\section{Endereço para correspondência}

Giovan Longo

Colégio Marista Rosário

Praça Dom Sebastião, 2

Independência, 90035-080

Porto Alegre, RS, Brasil antes da publicação. 